\title{
DIAGNOSTIC DILEMMA AND TREATMENT CHALLENGES IN IDIOPATHIC GRANULOMATOUS MASTITIS
}

\author{
Humera Latif, Syeda Rifaat Qamar Naqvi, Razia Bano, Nida Farrukh, Kishwar Ali*, Faiza Sana \\ Combined Military Hospital/National University of Medical Sciences (NUMS) Rawalpindi Pakistan, *Fauji Foundation Hospital Rawalpindi Pakistan
}

\begin{abstract}
Objective: To outline diagnostic difficulties and problems in the treatment of Idiopathic Granulomatous Mastitis Study Design: Prospective observational study.

Place and Duration of Study: Breast clinic, Combined Military Hospital Rawalpindi, from Aug 2019 to Jul 2020.

Methodology: Patients with tender mass with or without signs of inflammation, mass with abscess, sinus formation, and with recurrent abscesses were included. Those cases were labelled as IGM whose histopathology showed granulomatous mastitis with no evidence of malignancy and tissue cultures were negative. Patients with mild to moderate symptoms were treated with reassurance, analgesia and multivitamins. Abscesses were treated with incision \& drainage and empirical antibiotics for 1-2 weeks. All these patients were followed at 1, 3, 6 and 12 months.

Results: A total of 35 patients fulfilled the criteria for Idiopathic Granulomatous Mastitis and were included in the study. Two patients had lactational abscess, 3 had bilateral disease and 1 patient was with diabetes $0 \%$ patients were having mass with abscess; spontaneous resolution was observed in majority of them with a few requiring incision and drainage. Of $31.4 \%$ presented with tender mass only; majority of them resolved with observation, except mass excision in two patients, $19.7 \%$ presented with discharging sinuses with underlying mass; among them $71 \%$ responded to conservative treatment while $29 \%$ were treated with anti-tuberculous therapy for recurrent sinuses. $8.5 \%$ presented with spontaneously ruptured abscesses with sinuses; they were managed conservatively.

Conclusion: We concluded that Idiopathic Granulomatous Mastitisis a benign self-limiting disease which can be effectively managed with conservative treatment.
\end{abstract}

Keywords: Idiopathic granulomatous mastitis, Steroids, Self- limiting.

This is an Open Access article distributed under the terms of the Creative Commons Attribution License (http://creativecommons.org/licenses/by/4.0), which permits unrestricted use, distribution, and reproduction in any medium, provided the original work is properly cited.

\section{INTRODUCTION}

Idiopathic granulomatous mastitis (IGM) is a benign uncommon inflammatory condition with unknown etiology, characterized by chronic granulomatous inflammation of the breast. It is a challenging clinical condition for the treating surgeon due to its uncommon presentation, and resemblance to breast carcinoma. Ideal diagnostic modality and optimal treatment is still under trial ${ }^{1}$.

Common presentation is skin inflammation with or without sinus formation, tender mass only, mass with recurrent abscesses, may also present as mass with nipple retraction which resembles carcinoma breast, usually in the third or fourth decade of life $^{2}$. The exact etiology of idiopathic granulomatous mastitis is still uncertain. It may be caused by various infectious agents, autoimmune process, oral contraceptive pills, lactation, hormonal imbalance, smoking and a 1antitrypsin deficiency ${ }^{3}$.

A high index of suspicion is required to establish a diagnosis after excluding infective and autoimmune

Correspondence: Dr Humera Latif, Surgery Department, Combined Military Hospital, Rawalpindi Pakistan

Received: 21 Apr 2021; revised received: 23 Apr 2021; accepted: 26 Apr 2021 causes. The mammographic findings of IGM is often focal asymmetry while at ultrasound it appears as a hypoechoic mass with irregular margins ${ }^{4}$.

To differentiate it from other granulomatous diseases like sarcoidosis, tuberculosis and Wegener's granulomatosis, tissue diagnosis is mandatory ${ }^{5}$. The hallmark of IGM on histopathology arenoncaseating granulomas of lobulo-centric pattern associated with micro abscesses 6 .

IGM is a self-resolving disease with a prolonged but benign clinical course that includes periods of resolution and exacerbation. Eventually the disease resolves spontaneously inmost of the cases. For this reason, patience with the natural history of IGM is important both on the part of patient and on the part of the treating physician?

Different treatment options tried includes conservative approach with reassurance and symptomatic treatment, oral and local corticosteroid therapy, methotrexate, empirical anti tuberculous treatment and short courses of antibiotics. In case of recurrent abscesses, surgical drainage is mandatory ${ }^{8}$.

The aim of this study was to see the demographic details, clinical features and time for spontaneous 
resolution. In our study majority of the patients had complete resolution in periods of 9 months.

\section{METHODOLOGY}

This prospective observational study was performed at breast clinic, Combined Military Hospital Rawalpindi, from August 2019 to July 2020. Approval was taken from the hospital ethical review board (60/07/20-31). All patients who presented with tender mass with or without signs of inflammation, mass with abscess, sinus formation, and with recurrent abscesses were included in the study through convenient sampling. Male patients and patients having breast cancerin antibiotics for 1-2 weeks. All these patients were followed at 1, 3, 6 and 12 months. Data was analyzed using SPSS 21. Qualitative variables were summarized as number and frequency.

\section{RESULTS}

A total of 85 patients presented with chronic inflammation and recurrent abscesses, out of which 35 fulfilled the criteria for IGM and were included in the study. Age range was 22-55 years with a mean of 33.12 years. Out of these 35 patients, 2 had lactational abscess, 1 patient was with diabetes mellitus while 3 had bilateral disease.

Table: Presentation \& treatment.

\begin{tabular}{l|c|l}
\hline Presentation & No. of Patients & Treatment and Follow Up \\
\hline Tender Mass only & $11(31.4 \%)$ & $\begin{array}{l}\text { Reassurance, analgesia } \\
\text { Mass excisionin selective patients with progressive disease (on patient wish) } \\
\text { In majority of cases spontaneous resolution occurred in 6 months and after 9 } \\
\text { months only thickening was palpable }\end{array}$ \\
\hline Mass with abscess & $14(40 \%)$ & $\begin{array}{l}\text { Needle aspiration / Incision \& drainage plus empirical antibiotics } \\
\text { Spontaneous resolution observed in majority of cases after 6-7 months }\end{array}$ \\
\hline $\begin{array}{l}\text { Discharging sinuses } \\
\text { with underlying mass }\end{array}$ & $7(19.7 \%)$ & $\begin{array}{l}5(71 \%) \text { patients had complete resolution of symptoms with 1 year } \\
\text { conservative treatment } \\
2(29 \%) \text { patients had progressive disease with recurrent sinuses after 6 } \\
\text { months of conservative treatment; they responded to empirical anti } \\
\text { tuberculous therapy for 4 months after consultation with infectious disease } \\
\text { specialist (despite negative AFB cultures) }\end{array}$ \\
\hline $\begin{array}{l}\text { Spontaneously ruptured } \\
\text { abscess with sinuses } \\
\text { (without mass) }\end{array}$ & $3(8.5 \%)$ & $\begin{array}{l}\text { Conservatively managed with daily dressing and resolved within 1 year. } \\
\text { In 2 cases, recurrent sinuses with abscesses developed at 9 months which } \\
\text { resolved with antibiotics. }\end{array}$ \\
\hline
\end{tabular}

addition to Idiopathic Granulomatous Mastitis were excluded. Inaddition, of Open biopsy was performed in cases presenting with abscess and sinuses while core biopsy for cases with masses. Tissue wassent for histopathology, bacterial, fungal, and tuberculosis cultures. Those cases were labelled as Idiopathic granulomatous mastitis whose histopathology showed granulomatous mastitis with no evidence of malignancy and tissue cultures were negative. The demographic and clinical data i.e. name, age, and patient response to treatment was recorded on Proforma.

Patients with mild to moderate symptoms were treated conservatively with reassurance, analgesia and multivitamins for improvement of their immunity. Patients with sinus formation were offered conservative approach with short follow up or a course of oral steroids after consultation with Infectious disease specialist. Most patients opted for observation as compliance with prolong course of steroids and its complications was poor. Those presented with abscess were treated with incision \& drainage and empirical

\section{DISCUSSION}

Idiopathic granulomatous mastitis, reported by Kessler \& Wolloch for the first time in 1972, is a rare, benign and chronic inflammatory breast disease with no known cause that mainly affects female of child bearing age. It has variable presentation but most commonly presents as a hard breast lump. As the disease advances, features that mimic chronic breast infections and inflammatory breast cancer like nipple inversion, peaud'orange, erythema, ulcer and sinuses can occur. These features make diagnosis difficult ${ }^{9}$.

The common presentation which we observed was a tender breast mass with or without local and systemic signs of inflammation, mass with abscesses and sinus formation, spontaneously ruptured abscesses and sinuses without mass. Additional findings observed were erythema nodosum and bilateral ankle arthritis.

Idiopathic granulomatous mastitis is a very complicated condition that poses difficulties in diagnosis and treatment. It's a diagnosis of exclusion where we 
exclude breast malignancy and chronic specific breast infections by tissue culture and histopathology. Breast ultrasound, mammography and MRI breast may be performed to reach a diagnosis. Ultrasound may show hypoechoic masses with increased vascularity and multiple abscesses. Mammographically it may present as focal asymmetry, architectural distortion or irregular mass. MRI may show micro abscesses with irregular enhancing or non-enhancing masses ${ }^{4}$.

Uptill now there is no set standard treatment protocol available for this challenging condition. The different treatment options offered to these patients includes; oral or topical steroids, methotrexate, azathioprine, colchicine, empirical antituberculous treatment, conservative treatment with reassurance and improving immunity, incision and drainage of abscess and empirical antibiotic therapy and surgical excision of mass as a last resort in resistant or suspicious cases $^{10}$.

The commonest presentation of IGM which we observed in our study was a tender mass with abscess $(40 \%)$. We performed needle aspiration for deep lesions and incision \& drainage for large superficial abscesses and started empirical antibiotic therapy for 1-2 weeks. Majority of these patients showed complete resolution in 6-7 months. Joseph $\mathrm{KA}^{11}$ observed in their study that $33 \%$ of the IGM patients presented with purulent masses \& $50 \%$ had skin changes. They used needle aspiration and topical antibiotics to treat these patients along with steroids.

As IGM is a very challenging condition to treat, for this reason the optimal treatment remains controversial. Most clinicians suggest steroids for its treatment because of its autoimmune nature. The initial response observed with oral steroids was good in most of the studies however relapse was noted in almost half of the responders after discontinuation of steroids, which was treated with a second course of low dose steroids in combination with methotrexate. The problems associated with steroids are; compliance, prolonged course, relapse after discontinuation of treatment, drug related side effects ${ }^{11,12}$.

Some authors reported the use of methotrexate (MTX) as alternative or in combination with steroids in patients who has a relapse of the disease after discontinuation of methotrexate. In one study, the initial response rate observed with MTX alone and in combination with steroids was $100 \%$ however, $17.6 \%$ patients had a relapse on discontinuation of the treatment. Side effects associated with MTX are; hair loss, deranged liver functions and compliance ${ }^{13,14}$.

Anti-tuberculous drugs have been used in the treatment of atypical cases of IGM not responding to anti-inflammatory drugs with high clinical suspicious of tuberculous mastitis. Most of diagnostic test performed for breast TB including ZN stain and AFB cultures are inconclusive because of the paucibacillary nature of the disease ${ }^{15}$. Joseph et al ${ }^{11}$ reported complete remission of the disease to anti-tuberculous therapy in atypical cases of IGM, not responding to anti-inflammatory drugs, whose clinical suspicious for TB mastitis was high.

In our study, we planned to manage these patients with observation, reassurance and symptomatic treatment. All the patients were educated about the disease and its benign natural course. They were told that complete resolution will take upto 12 months and they may experience a few exacerbations of the disease in between. No patient received steroids or methotrexate in our series. Incision \& drainage was done in patients with abscesses while the tender mass was excised in two patients on their wish. Two patients received antituberculous treatment for recurrent sinus after six months of conservative treatment. We observed that majority of these patients can be treated with close observation and symptomatic treatment. Our results are comparable with the study by Bouton et al ${ }^{16}$ who also managed their patients successfully with observation only. Patience on the part of patient and treating physician can avoid unnecessary surgery and medications with associated side effects and financial cost.

Although clinical and radiological findings of patients with GM may mimic those of breast carcinoma, but women of childbearing age, with a recent history of pregnancy or high prolactin level and newly tender mass-like lesion, in addition to new focal asymmetry on mammogram and heterogeneous hypoechoic irregular-shaped mass on ultrasound exam, should raise concern for $\mathrm{GM}^{17,18}$. Non-invasive approach and clinical follow-up were the preferred treatment method.

\section{CONCLUSION}

From our experience, we suggest that close observation is a safe and feasible treatment option for this benign and self-resolving condition. It should be offered to all patients with IGM to reduce financial burden and to avoid potential side effects of prolonged medications. 


\section{CONFLICT OF INTEREST}

This study has no conflict of interest to be declared by any author.

\section{REFERENCES}

1. Davis J, Cocco D, Matz S, Hsu CH, Brown MJ, Lee J, et al. Reevaluating if observation continues to be the best management of idiopathic granulomatous mastitis. Surgery 2019; 166(6): 1176-80.

2. Poovamma CU, Pais VA, Dolas SC, Prema M, Khandelwal R, Nisheena R. Idiopathic granulomatous mastitis: a rare entity with a variable presentation. Breast Dis 2014; 34(3): 101-04.

3. Altintoprak F, Kivilcim T, Ozkan OV. Aetiology of idiopathic granulomatous mastitis. World J Clin Cases 2014; 2(12): 852-58.

4. Fazzio RT, Shah SS, Sandhu NP, Glazebrook KN. Idiopathic granulomatous mastitis: imaging update and review. Insights Imag 2016; 7(4): 531-39.

5. Benson JR, Dumitru D. Idiopathic granulomatous mastitis: presentation, investigation and management. Future Oncol 2016; 12(11): 1381-94.

6. Naraynsingh V, Hariharan S, Dan D, Harnarayan P, Teelucksingh S. Conservative management for idiopathic granulomatous mastitis mimicking carcinoma: case reports and literature review. Breast Dis 2010; 31(1): 57-60.

7. Altintoprak F, Kivilcim T, Yalkin O, Uzunoglu Y, Kahyaoglu Z. Topical steroids are effective in the treatment of idiopathic granulomatous mastitis. World J Surg 2015; 39(11): 2718-23.

8. Erozgen F, Ersoy YE, Akaydin M, Memmi N, Celik AS, Celebi F, et al. Corticosteroid treatment and timing of surgery in idiopathic granulomatous mastitis confusing with breast carcinoma. Breast Cancer Res Treat 2010; 123(2): 447-52.
9. Mahmodlou R, Dadkhah N, Abbasi F, Nasiri J, Valizadeh R. Idiopathic granulomatous mastitis: dilemmas in diagnosis and treatment. Electron Physician 2017; 9(9): 5375-79.

10. Lei X, Chen K, Zhu L, Song E, Su F, Li S. Treatments for idiopathic granulomatous mastitis: systematic review and meta-analysis. Breast Feed Med 2017; 12(7): 415-21.

11. Joseph KA, Luu X, Mor A. Granulomatous mastitis: a New York public hospital experience. Ann Surg Oncol 2014; 21(13): 4159-63.

12. Çetin K, Sıkar HE, Göret NE, Rona G, Barışık NÖ, Küçük HF, et al. Comparison of topical, systemic, and combined therapy with steroids on idiopathic granulomatous mastitis: a prospective randomized study. World J Surg 2019; 43(11): 2865-73.

13. Haddad M, Sheybani F, Arian M, Gharib M. Methotrexate-based regimen as initial treatment of patients with idiopathic granulomatous mastitis. Breast J 2020; 26(2): 325-27.

14. Peña-Santos G, Ruiz-Moreno JL. Mastitis granulomatosa-idiopáticatratada con esteroidesy metotrexato [Idiopathic granulomatous mastitis treated with steroids and methotrexate]. Ginecol Obstet Mex 2011; 79(6): 373-76.

15. Na Seo HR, Na KY, Yim HE, Kim TH, Kang DK, Oh KK, et al. Differential diagnosis in idiopathic granulomatous mastitis and tuberculous mastitis. J Breast Cancer 2012; 15: 111-18.

16. Bouton ME, Jayaram L, O'Neill PJ, Hsu CH, Komenaka IK. Management of idiopathic granulomatous mastitis with observation. Am J Surg 2015; 210(2): 258-62.

17. Shin YD, Park SS, Song YJ, Son SM, Choi YJ. Is surgical excision necessary for the treatment of Granulomatous lobular mastitis? BMC Womens Health 2017; 17(1): 49.

18. Barreto DS, Sedgwick EL, Nagi CS, Benveniste AP. Granulomatous mastitis: etiology, imaging, pathology, treatment, and clinical findings. Breast Cancer Res Treat 2018; 171(3): 527-34. 